\title{
DESONERAÇÃO DOS RENDIMENTOS DO CAPITAL NO BRASIL E SEUS IMPACTOS NO DESENVOLVIMENTO ECONÔMICO ${ }^{1}$
}

\author{
Luciana Grassano de Gouvêa Melo* \\ Raphael Henrique Lins Tiburtino dos Santos**
}

\section{RESUMO}

O artigo analisa a relação entre a desoneração fiscal dos rendimentos do capital no Brasil e o baixo desenvolvimento econômico do país. Segundo Thomas Piketty, quando a taxa de retorno do capital excede de forma significativa a taxa de crescimento da produção e dos salários, observa-se o aumento da concentração de riqueza e a consequente diminuição do crescimento econômico. Nesse contexto, apesar de figurar entre os países mais desiguais do mundo, o Brasil possui um sistema tributário extremamente regressivo, que desonera os rendimentos do capital em detrimento dos rendimentos do trabalho, agravando o problema da desigualdade e dificultando o desenvolvimento econômico do país.

Palavras-chaves: desigualdade de renda; desenvolvimento econômico; desoneração fiscal; rendimentos do capital.

\section{INTRODUÇÃO}

Nelson Saldanha ensina que o formalismo - assim compreendido o apego exagerado à forma em detrimento do conteúdo - esteve presente na própria fundação do pensamento jurídico moderno. Desde o advento da modernidade, com a expansão do método cartesiano para os diversos ramos do conhecimento, até os dias de hoje, é possível observar um claro distanciamento entre as teorias do direito e um enfoque empírico voltado à realidade social ${ }^{2}$. Aquela que Theodor Viehweg uma vez chamou de "aporia fundamental do direito", isto é, "a questão do que seja justo aqui e agora"3, há tempo vem sendo substituída, no âmbito da dogmática jurídica, por problemas puramente metodológicos e conceituais, sempre sob o pretexto de assim conferir à "ciência do direito" uma suposta neutralidade axiológica ${ }^{4}$.

Não é preciso muito esforço, todavia, para perceber que essa autoproclamada objetividade - de toda inalcançável na prática - esconde em verdade um conservadorismo velado, que se coloca em prol da manutenção do status quo. De fato, em termos histórico-culturais, Saldanha correlaciona o formalismo, inclusive o jurídico, ao liberalismo, traçando um paralelo entre o ideal de neutralidade científica daquele e a tentativa de esvaziamento e despolitização do debate público por parte deste ${ }^{5}$.

${ }^{1}$ Este artigo foi elaborado para a conclusão da disciplina do PPGD/UFPE "Tributação, economia e desenvolvimento social", ministrada pela co-autora professora Luciana Grassano de Gouvêa Melo, e a partir das referências bibliográficas discutidas em sala de aula, semestre 2020.2.

* Mestre e Doutora em Direito pela UFPE (2006), com estágio doutoral (2006) na Universidade Lusíada em Lisboa e pós-doutoral (2014), na Universidade de Bologna, na Itália (ambos pela CAPES). É professora da graduação, mestrado e doutorado em Direito da UFPE, ex-diretora da Faculdade de Direito do Recife/UFPE (2007 a 2015) e Procuradora do Estado de Pernambuco. Email: luggmelo@gmail.com

** Mestrando em direito pelo Programa de Pós-Graduação em Direito da Universidade Federal de Pernambuco (PPGD-UFPE).

2 SALDANHA, Nelson. Da teologia à metodologia: secularização e crise do pensamento jurídico. Belo Horizonte: Del Rey, 1993. p. 99.

VIEHWEG, Theodor. Tópica e jurisprudência. Brasília: UnB; Brasília: Ministério da Justiça, 1979. p. 88.

SALDANHA, Nelson. Ibidem, p 98.

Ibidem, p. 98. 


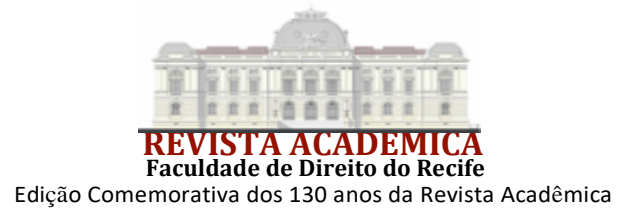

No âmbito das ciências econômicas, até muito recentemente, a teoria mais bem aceita para explicar a relação entre desigualdade de renda e crescimento econômico foi apresentada por Simon Kuznets, em artigo publicado ainda nos idos da década de 60, no famoso periódico The American Economic Review. De forma bastante sucinta, a hipótese de Kuznets é de que, à medida que a economia cresce, a concentração de riqueza tende a se agravar, mas somente até determinado nível. Uma vez alcançado esse grau máximo, a desigualdade estabilizar-se-ia, até decrescer espontaneamente $^{12}$. Contudo, apesar de bem recebidas no meio acadêmico, o fato é que as conclusões de Kuznets carece de dados confiáveis, a ponto de o próprio autor admitir que o seu trabalho se resumia em 5\% de informação empírica e $95 \%$ de especulação, e que parte desta provavelmente estava enviesada por seu próprio wishful thinking ${ }^{13}$.

Nesse contexto de incerteza, o trabalho de Piketty foi capaz de lançar novas luzes sobre o velho e aparentemente insolúvel problema da desigualdade. Os dados reunidos pelo economista francês mostram que as conjecturas de Kuznets eram não apenas equivocadas, mas extremamente otimistas. Para Piketty, Kuznets teria negligenciado o fato de que as duas guerras mundiais, bem como as políticas públicas que lhes sucederam, tiveram um papel marcante na redução das desigualdades durante o século XX. Não houve, portanto, nada de natural ou espontâneo nesse processo. Mais que isso, contrariando as predições de Kuznets, observou-se nas décadas de 70 e 80 uma rápida retomada do crescimento da desigualdade, porém com significativas variações de país para país, reforçando o entendimento de que diferenças políticas e institucionais têm papel relevante na dinâmica dos níveis de concentração de riqueza ${ }^{14}$.

Mas, se a hipótese de Kuznets parece não se confirmar, como então explicar a correlação entre desigualdade de renda e concentração de riqueza? Para Piketty, as disputas sobre distribuição de renda sempre tiveram como questão central qual proporção dos resultados deve ser destinada aos salários e qual deve ser direcionada aos lucros. Ou, em outras palavras, como os rendimentos da produção devem ser divididos entre trabalho e capital ${ }^{15}$. Uma vez reformulado o problema nesses termos, Piketty propõe a tese de que, sempre que a taxa de retorno do capital excede de forma significativa a taxa de crescimento da produção e dos salários, o capitalismo automaticamente cria desigualdades arbitrárias e insustentáveis, que minam os valores meritocráticas sobre os quais se fundam as sociedades democráticas ${ }^{16}$.

De acordo com Piketty, isso se explica porque, quando a taxa de retorno do capital é superior à taxa de crescimento da produção, consequentemente a parcela das riquezas que são fruto de herança crescerá mais rapidamente que a obtida pelo esforço do trabalho. Nas palavras de Piketty:

\begin{abstract}
Quando a taxa de retorno do capital significativamente supera a taxa de crescimento da economia (como aconteceu durante boa parte da história até o século XIX e como provavelmente será de novo o caso do século XXI), então logicamente segue que a riqueza herdada cresce mais rápido que a produção e os salários. Herdeiros precisam poupar apenas uma porção dos seus rendimentos do capital para ver que o capital cresce mais rapidamente que a economia como um todo. Sob estas condições, é quase inevitável que a riqueza herdada refreará a riqueza acumulada durante uma vida de trabalho por uma margem bastante larga, e a concentração do capital atingirá níveis bastante extremos níveis potencialmente incompatíveis com os valores meritocráticos e princípios de justiça social fundamentais para as sociedades democráticas modernas. (tradução livre) ${ }^{17}$
\end{abstract}

12 KUZNETS, Simon. Economic growth and income inequality. American Economic Review, v. 45, n. 1, mar. 1995, p. 1-28.

13 Ibidem, p. 26.

14 Ibidem, p. 237

15 PIKETTY, Thomas. Capital in the twenty-first century. Trad. Arthur Goldhammer. Cambridge, London: The Belknap Press of Harvard University Press, 2014. p. 39.

16 Ibidem, p. 1, 26, 77, 377-378.

17 Ibidem, p. 26. 
Para os limites do presente estudo, interessa especificamente a circunstância de que esse cenário retratado por Piketty, no qual os investimentos em capital são mais vantajosos que os investimentos na produção e no trabalho, gera um desincentivo à inovação e ao empreendedorismo, ao mesmo tempo em que estimula o rentismo e a especulação. A concentração do capital e a desigualdade de renda, nesse sentido, revelam-se prejudiciais ao próprio crescimento econômico do país, apenas beneficiando um percentual ínfimo da população que compõe a classe dos super ricos.

Mas Piketty não é o único a afirmar que desigualdade e ineficiência econômica andam de mãos dadas. Pelo contrário, em discurso proferido nas Grandes Conférences Catholiques, no ano de 2015, a então Diretora-Geral do Fundo Monetário Internacional (FMI), Christine Lagarde, referiu-se a um "novo consenso crescente", no sentido de que "a desigualdade excessiva de renda na verdade reduz a taxa de crescimento econômico e torna o crescimento menos sustentável com o tempo ${ }^{18 " . ~ L a g a r d e ~ f a z i a ~ a l u s a ̃ o ~ e s p e c i f i c a m e n t e ~ a ~ d o i s ~ a r t i g o s ~ a ̀ ~ e ́ p o c a ~ r e c e ́ m ~ p u b l i c a d o s ~ p e l o ~}$ FMI. O primeiro deles conclui taxativamente que a distribuição de renda representa um dos mais robustos e importantes fatores associados à sustentabilidade do crescimento econômico no médio e longo prazo. Nesse sentido, uma diminuição de $10 \%$ no índice de desigualdade pode prolongar o período de crescimento econômico de um país em $50 \%{ }^{19}$. O segundo demonstra a existência de uma relação inversa entre concentração de renda e crescimento do PIB. Com efeito, enquanto um aumento de $1 \%$ na participação dos $20 \%$ mais ricos na renda total do país resulta em um decréscimo de $0,08 \%$ no PIB nos próximos cinco anos, esse mesmo aumento de $1 \%$ na participação dos rendimentos totais, quando direcionada à faixa dos $20 \%$ mais pobres, leva a um aumento do PIB em $0,38 \%^{20}$. Em suma, a desigualdade de renda, além de um problema ético e humanitário, é também um empecilho ao desenvolvimento econômico.

É importante destacar, por fim, que, para Piketty, a desigualdade de renda não decorre de uma falha ou imperfeição do mercado. Pelo contrário, quanto mais perfeito é o mercado, no sentido econômico da expressão, maior é a probabilidade de a taxa de retorno do capital ser superior à taxa de crescimento da produção e dos salários. Maior, portanto, a tendência à desigualdade de renda. Da mesma forma, segundo Piketty, a concentração de riqueza não é um fenômeno inexorável e perpétuo, mas apenas um dos vários caminhos possíveis a ser seguidos ${ }^{21}$. É justamente nesse sentido que Piketty defende uma forte tributação sobre os rendimentos do capital como medida necessária e premente para tentar frear a onda de desigualdade de renda que tem inundado o século $\mathrm{XXI}^{22}$.

\section{O CENÁRIO BRASILEIRO: DESIGUALdAdE PERSISTENTE E TRIBUTAÇÃO REGRESSIVA}

A desigualdade social tem se mostrado um dos poucos fenômenos perenes na história da humanidade. É verdade que arranjos das relações de poder sofreram inúmeras alterações ao longo

18 Disponível em: https://www.imf.org/external/lang/portuguese/np/speeches/2015/061715p.pdf. Acesso em: 12 abr. 2021.

19 BERG, Andrew G.; OSTRY, Jonathan D. Inequality and unsustainable growth: two sides of the same coin? Fundo Monetário Internacional, abr. 2011, p. 13. Disponível em: https://www.imf.org/external/pubs/ft/sdn/2011/sdn1108.pdf. Acesso em: 12 abr. 2021.

20 DABLA-NORRIS, Era et al. Causes and consequences of income inequality: a global perspective. Fundo Monetário Internacional, jun. 2014, p. 7. Disponível em: https://www.imf.org/en/Publications/Staff-DiscussionNotes/Issues/2016/12/31/Causes-and-Consequences-of-Income-Inequality-A-Global-Perspective-42986. Acesso em: 12 abr. 2021.

21 PIKETTY, Thomas. Capital in the twenty-first century. Trad. Arthur Goldhammer. Cambridge, London: The Belknap Press of Harvard University Press, 2014. p. 27.

22 Ibidem, p. 515-539. 
do tempo, sendo a desigualdade um acontecimento de características multidimensionais ${ }^{23}$. Mas isso não muda o fato de que os períodos nos quais foi possível observar uma tendência de desconcentração de renda, além de terem sido episódicos e excepcionais, precisaram ser conquistados a duras penas, sempre encontrando forte resistência por parte dos setores reacionários ${ }^{24}$.

De modo geral, Márcio Pochmann aponta dois padrões históricos de desconcentração de riqueza. O primeiro está ligado aos processos revolucionários burgueses e socialistas, que implicaram uma ruptura com antigos regimes sociais, econômicos e políticos. O segundo padrão diz respeito às chamadas reformas civilizatórias, fruto sobretudo da expansão do regime democrático. A disseminação da democracia possibilitou um considerável aumento de representatividade no poder, o que permitiu a implementação de ao menos três grandes reformas: agrária, com a distribuição de terras à população; tributária, através da instituição de sistemas de tributação fundados na noção de progressividade; e social, com a garantia de um padrão de vida mínima a todos, através da universalização de bens e serviços públicos possibilitada pelas receitas obtidas com a arrecadação de tributos. Essas reformas, em conjunto, propiciaram uma considerável diminuição na concentração de riqueza nos países desenvolvidos, fomentando a redistribuição de renda entre a população ${ }^{25}$.

A questão é que, diversamente do que ocorreu nos países desenvolvidos, em que foi possível observar uma redução dos índices de desigualdade, sobretudo nos anos que sucederam as grandes guerras, Pochmann ressalta que "a concentração de renda e riqueza é uma marca inalienável no Brasil" "26. O Brasil não passou por grandes revoluções, sejam de origem burguesa ou socialista. Da mesma forma, as reformas agrária, tributária e social nunca chegaram a ser implementadas. Daí que, independentemente da forma de governo ou do regime político a que esteve submetido, o país sempre manteve altos níveis de concentração de renda ${ }^{27}$.

De fato, não é nenhum exagero afirmar que o Brasil é um dos países mais injustos e desiguais do mundo. Apesar de figurar como a décima segunda maior economia em termos de Produto Interno Bruto, já tendo inclusive ocupado a sexta colocação, de acordo com dados oficiais divulgados pelo Banco Mundial, o Brasil amarga a décima posição no ranking de países com maior

23 POCHMANN, Márcio. Desigualdade econômica no Brasil. São Paulo: Ideias \& Letras, 2015. p. 1.

24 A resistência aos avanços progressistas não se reduz apenas à coação física, mas abrange também a violência simbólica. Albert O. Hirschman identifica três teses ou padrões retóricos que aparecem recorrentemente no discurso reacionário: a tese da perversidade, consistente em sustentar que as ações promovidas com o objetivo de implementar conquistas progressistas na sociedade tem na verdade um efeito perverso, na medida em que levam, inevitavelmente, ao resultado oposto do pretendido; a tese da inutilidade, segundo a qual as tentativas de mudança do status quo são inócuas, pois os resultados obtidos são meramente superficiais, não atingindo as raízes que estruturam a vida em sociedade; e a tese do risco, onde se apela para uma suposta relação entre custos e benefícios, para defender que a concretização de novos direitos apenas é obtida às custas de outros direitos já consolidados. E interessante notar que as três teses de Hirschman são facilmente percebidas no discurso reacionário brasileiro. A tese da perversidade, por exemplo, aparece no debate público para criticar a instituição do Imposto Sobre Grandes Fortunas, sendo reiteradas as alegações de teóricos conservadores de que a medida levaria a uma queda, e não ao aumento, da arrecadação, pois supostamente incentivaria o êxodo dos super ricos para países de tributação mais favorecida (muito embora esses países nunca cheguem a ser nominados). A tese da inutilidade é frequentemente utilizada por figuras reacionárias ao se referirem ao Programa Bolsa Família, no sentido de que a referida política de renda mínima não teria alcançado vitórias significativas em termos de redistribuição de renda, querendo com isso desmerecer os avanços sociais conquistados por governos de cunho progressista. Também a tese do risco faz parte do discurso corrente reacionário, a exemplo da alegação de que o aumento de impostos configura uma pretensa ameaça à liberdade individual dos cidadãos e à propriedade privada. HIRSCHMAN, Albert O. The rhetoric of reaction: perversity, futility, jeopardy. Cambridge, Londres: The Belknap Press of Harvard University Press, 1991.

25 POCHMANN, Márcio. Desigualdade econômica no Brasil. São Paulo: Ideias \& Letras, 2015. p. $24-32$.

26 Ibidem, p. 32.

27 Ibidem, p. 32-38 
taxa de concentração de renda, calculada através do coeficiente de Gini ${ }^{28}$.

O grave quadro de desigualdade no qual o Brasil está inserido foi exposto em minúcias pelo economista irlandês e pesquisador da Oxfam, Marc Morgan. A partir da reuniões de dados de pesquisas domiciliares e fiscais, referentes ao período de 2001 a 2015, Morgan buscou apresentar novas evidências sobre o problema da desigualdade de renda no Brasil, com o objetivo de responder três questionamentos centrais: primeiro, como está situada a concentração de renda no Brasil, inclusive quando comparado a outros países; segundo, como o aumento da renda média verificada no período foi distribuído entre os diferentes grupos de renda; e, terceiro, como se dá a tributação da renda da pessoa física no país e de que forma aperfeiçoá-la ${ }^{29}$.

Morgan explica que os estudos que se debruçaram sobre o problema da desigualdade no Brasil tinham em comum o fato de se basearem exclusivamente nas estatísticas construídas a partir de informações autodeclaradas pela população, obtidas através de pesquisas domiciliares realizadas pelos institutos oficiais de pesquisa. Esses dados se mostravam pouco confiáveis por diversas razões, sendo a principal delas a resistência da camada mais rica da população em conceder espontaneamente informações relacionadas a sua renda e patrimônio, ou mesmo de participar de pesquisas oficiais ${ }^{30}$. Nesse sentido, com a utilização dos relatórios fiscais publicados pela Secretaria da Receita Federal do Brasil ("Grandes Números DIRPF Ano Calendário 20072015"), relativos às declarações de imposto de renda das pessoas físicas, de apresentação obrigatória, Morgan pôde extrair novas conclusões a respeito da evolução da concentração de renda no Brasil ${ }^{31}$.

Em relação ao primeiro questionamento suscitado pela pesquisa - como está distribuída a concentração de renda no Brasil -, Morgan constatou que, no ano de 2015, os $10 \%$ mais ricos da população recebem mais da metade da renda do país (53\%), os $40 \%$ intermediários detêm cerca de $34,4 \%$ dos rendimentos, enquanto que os $50 \%$ mais pobres auferem pouco mais que um décimo de toda renda produzida (10,9\%). Há, portanto, uma evidente discrepância na distribuição de renda entre o topo e base da pirâmide brasileira, até então subestimada pelas estatísticas produzidas a partir das pesquisas domiciliares. Além disso, apesar de entre os anos de 2001 a 2015 ter havido uma redução na concentração de renda dos mais ricos (de 54,6\% para 53\%) e um incremento na participação dos mais pobres (de $10,6 \%$ para 12,6\%), essa mudança foi tímida e muito menos significativa do que apontavam outros estudos produzidos. Os novos dados obtidos se tornam ainda mais eloquentes quando comparados com a realidade de outros países marcados pela desigualdade de renda, ficando o Brasil atrás apenas da África do Sul no que diz respeito à concentração de renda entre os $10 \%$ mais ricos ${ }^{32}$.

Quanto ao segundo questionamento, foi possível um crescimento na renda média da população brasileira de 26,7\% entre 2001 e 2015. Em consonância com a leve desconcentração observada no período, esse aumento foi mais significativo para os $50 \%$ da faixa mais pobre, cuja

28 Disponível em: https://data.worldbank.org/indicator/SI.POV.GINI. Acesso em: 12 abr. 2021.

29 MORGAN, Marc. Income inequality, growth and elite taxation in Brazil: new evidence combining survey and fiscal data, 2001-2015. Working Papers no 165, International Policy Centre for Inclusive Growth, fev. 2018 , p. 6. Disponível em: https://ideas.repec.org/p/ipc/wpaper/165.html. Acesso em: 12 abr. 2021.

30 MORGAN, Marc. Income inequality, growth and elite taxation in Brazil: new evidence combining survey and fiscal data, 2001-2015. Working Papers $n^{\circ}$ 165, International Policy Centre for Inclusive Growth, fev. 2018, p. 6 7. Disponível em: https://ideas.repec.org/p/ipc/wpaper/165.html. Acesso em: 12 abr. 2021.

${ }^{31}$ A despeito do inegável aumento da confiabilidade do estudo produzido por Morgan, propiciado pela incorporação dos dados fiscais disponibilizados pela RFB, a realidade brasileira pode ser ainda mais grave que a retratada pelo economista. Isso porque, como explica José Saldanha Sanches, os dois maiores problemas do direito fiscal contemporâneo correspondem à fraude fiscal (corrosão externa da tributação) e ao planejamento fiscal abusivo (corrosão interna da tributação). Trata-se, portanto, de comportamentos não cooperativos dos contribuintes, e que, por isso mesmo, não são mensuráveis com base nas informações prestadas pelos próprios sujeitos passivos em suas declarações obrigatórias. SANCHES, J. L. Saldanha. Justiça Fiscal. Lisboa: Fundação Francisco Manuel dos Santos, 2016.

32 Ibidem, p. 12-18. 


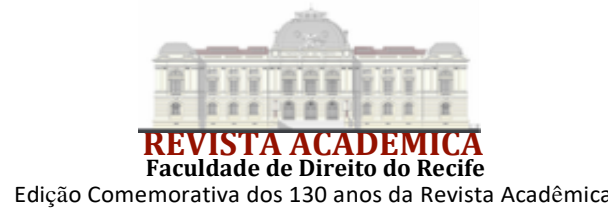

renda recebeu um incremento de $49,8 \%$, ao passo que a renda dos $10 \%$ do topo e dos $40 \%$ intermediários cresceu abaixo da média nacional (24,9\% e $23,5 \%$, respectivamente). No entanto, nota-se que, em razão dos escassos rendimentos auferidos pela camada mais pobre, o seu maior crescimento percentual, quando comparado ao das demais faixas, não se refletiu na participação de cada uma delas no crescimento médio total da renda brasileira. Nesse aspecto, os $10 \%$ mais ricos capturaram $47,9 \%$ do crescimento total de renda verificada no período, superior aos $19,8 \%$ capturados pela faixa inferior ${ }^{33}$.

Essa acentuada desigualdade de renda no Brasil, por sua vez, é em grande parte explicada por um sistema tributário extremamente regressivo ${ }^{34}$, que desonera o patrimônio e a renda, em especial dos mais ricos, ao passo em que impõe uma elevada carga tributária sobre o consumo. De fato, os esforços empreendidos na última década, especialmente com a publicação da Lei $\mathrm{n}^{\circ} 10.836$, de 9 de janeiro de 2004, que instituiu o programa de renda mínima condicionada "Bolsa Família", têm sido dificultados pela injusta tributação brasileira. Recente estudo publicado pela Associação Nacional dos Auditores Fiscais da Receita Federal do Brasil (Anfip) e pela Federação Nacional do Fisco Estadual e Distrital (Fenafisco) chama atenção para o fato de que, embora o Brasil tenha a política social mais efetiva dentre os países da América Latina, a contribuição dos impostos diretos na redução da disparidade de renda é praticamente nula, o que explica a baixa diminuição do coeficiente de Gini em comparação à média dos países da Organização para a Cooperação e Desenvolvimento Econômico $(\mathrm{OCDE})^{35}$. Nesses termos, a Anfip e a Fenafisco defendem a necessidade de medidas que fomentem a progressividade do sistema tributário brasileiro, ao mesmo tempo que assegurem a continuidade e ampliação dos programas de proteção social ${ }^{36}$.

\section{A DESONERAÇÃO DOS RENDIMENTOS DO CAPITAL NA PESSOA FÍSICA}

Falamos há pouco que os rendimentos podem ser divididos funcionalmente em rendimentos do capital, obtidos em decorrência da propriedade de um determinado bem ou direito (lucros, dividendos, ganho de capital etc.), e rendimentos do trabalho, pagos a título de remuneração a uma atividade prestada (salário). Dissemos também que, quando a taxa de retorno do capital é superior à taxa de crescimento da produção e dos salários, há um consequente aumento da desigualdade de renda, e que esta constitui um óbice para o crescimento econômico. Finalmente, mostramos como o Brasil sofre de uma persistente desigualdade de renda, onde um décimo da população "abocanha" mais da metade da riqueza produzida no país.

De posse dessas informações, não é difícil concluir que a solução dos problemas concernentes à distribuição de renda e ao desenvolvimento econômico do Brasil, por mais complexa que seja, perpassa necessariamente uma enérgica tributação dos rendimentos do capital, nunca inferior à carga tributária que recai sobre os rendimentos do trabalho. $\mathrm{O}$ que ocorre na prática, contudo, é o exato oposto disso.

Novamente recorrendo a Marc Morgan, podemos mensurar o potencial redistributivo do imposto de renda da pessoa física a partir de dois critérios. Primeiro, a equidade horizontal, no sentido de que as diferentes fontes de renda (do capital e do trabalho) devem ser submetidas à

33 MORGAN, Marc. Income inequality, growth and elite taxation in Brazil: new evidence combining survey and fiscal data, 2001-2015. Working Papers $n^{\circ}$ 165, International Policy Centre for Inclusive Growth, fev. 2018, p. 1819. Disponível em: https://ideas.repec.org/p/ipc/wpaper/165.html. Acesso em: 12 abr. 2021.

34 Sobre o tema, ver: MELO, Luciana Grassano de Gouvêa. Para entender o papel da tributação na desigualdade. In: MELO, Luciana Grassano de Gouvêa (org.). Justiça Fiscal. Estudos Críticos de problemas atuais. Belo Horizonte: Ed. Letramento, 2020. p. 21-36.

35 ASSOCIAÇÃO NACIONAL DOS AUDITORES DA RECEITA FEDERAL DO BRASIL (ANFIP) e FEDERAÇÃO NACIONAL DO FISCO ESTADUAL E DISTRITAL (FENAFISCO). Eduardo Fagnani (organizador). A reforma tributária necessária: diagnósticos e premissas. Brasília: ANFIP, FENAFISCO. São Paulo: Plataforma Política Social, 2018. p. 19-20.

36 Ibidem, p. 21. 
mesma estrutura de alíquotas. Segundo, a equidade vertical, segundo a qual as maiores rendas devem ser tributadas de forma proporcionalmente mais onerosa ${ }^{37}$.

Em relação à equidade horizontal, a renda proveniente do trabalho, regra geral, sofre incidência do imposto de renda "calculado de acordo com a tabela progressiva anual correspondente à soma das tabelas progressivas mensais vigentes nos meses de cada anocalendário", nos termos do artigo 79 do Regulamento do Imposto de Renda (RIR), aprovado pelo Decreto $n^{\circ}$ 9.580/2018. A última atualização das tabelas progressivas ocorreu no ano de 2015, com a publicação da Lei $n^{\circ} 13.149 / 2015$, que incluiu o acrescentou o inciso IX ao artigo $1^{\circ}$ da Lei $n^{\circ}$ 11.482/2007, sendo estabelecidas as seguintes bases de cálculo e alíquotas para os rendimentos auferidos a partir de abril do ano-calendário de 2015: isenção para rendimentos anuais iguais ou inferiores a $\mathrm{R} \$ 22.847,76$; alíquota de 7,5\% para rendimentos de $\mathrm{R} \$ 22.847,77$ até $33.919,80 ; 15 \%$, de $\mathrm{R} \$ 33.919,81$ até $\mathrm{R} \$ 45.012,60 ; 22,5 \%$, de $\mathrm{R} \$ 45.012,61$ a $\mathrm{R} \$ 55.976,16$; e 27,5\% para os rendimentos superiores a $\mathrm{R} \$ 55.976,16$.

Quanto aos rendimentos do capital, observa-se na legislação brasileira uma tributação extremamente favorecida, seja em comparação aos rendimentos do trabalho, seja à média observada nos países que compõem a OCDE. Esse esvaziamento da tributação do capital foi fruto da reforma neoliberal promovida por Fernando Henrique Cardoso ${ }^{38}$, cuja medida mais importante - e também mais danosa à progressividade do sistema tributário nacional - consistiu na promulgação da Lei $\mathrm{n}^{\circ}$ 9.249/1995, que alterou a legislação brasileira em dois aspectos fundamentais: concedeu isenção total aos valores distribuídos pela pessoa jurídica a título de lucros e dividendos à distribuição de lucros e dividendos pagos aos sócios e acionistas de pessoas jurídicas e criou os chamados juros sobre o capital próprio.

Salta aos olhos, de início, o benefício fiscal instituído pelo artigo 10 da Lei $\mathrm{n}^{\circ}$ 9.249/1995, que isenta do imposto de renda os lucros ou dividendos pagos ou creditados pelas pessoas jurídicas a seus sócios e acionistas. De acordo com nota técnica divulgada pela Associação Nacional dos Auditores Fiscais da Receita Federal do Brasil (Unafisco), dos países da OCDE, apenas o Brasil, a Letônia e a Estônia preveem isenção para os lucros e dividendos distribuídos ${ }^{39}$. Ainda segundo a referida nota, estima-se que a revogação do benefício guarda um potencial arrecadatório da ordem de $\mathrm{R} \$ 54$ bilhões por ano, isto já considerando a taxa de sonegação atual média brasileira ${ }^{40}$.

A segunda grande alteração promovida pelo governo FHC diz respeito à criação da figura dos juros sobre o capital próprio (JCP), instituída pelo art. $9^{\circ}$ da Lei ${ }^{\circ}$ 9.249/1995. Com base no referido instituto, a pessoa jurídica pode deduzir da base de cálculo do imposto de renda da pessoa jurídica e da contribuição social sobre o lucro líquido parcela da remuneração paga aos seus sócios e acionistas, criando assim uma espécie de despesa financeira fictícia ${ }^{41}$. Para os fins do presente

37 MORGAN, Marc. Income inequality, growth and elite taxation in Brazil: new evidence combining survey and fiscal data, 2001-2015. Working Papers n ${ }^{\circ}$ 165, International Policy Centre for Inclusive Growth, fev. 2018, p. 19-20. Disponível em: https://ideas.repec.org/p/ipc/wpaper/165.html. Acesso em: 12 abr. 2021.

38 INTROÍNI, Paulo Gil Hölck et al.Tributação sobre a renda da pessoa física: isonomia como princípio fundamental de justiça fiscal, p. 265. In: ASSOCIAÇÃO NACIONAL DOS AUDITORES DA RECEITA FEDERAL DO BRASIL (ANFIP) e FEDERAÇÃO NACIONAL DO FISCO ESTADUAL E DISTRITAL (FENAFISCO). Eduardo Fagnani (organizador). A reforma tributária necessária: diagnósticos e premissas. Brasília: ANFIP, FENAFISCO. São Paulo: Plataforma Política Social, 2018. p. 245-280.

${ }^{39}$ ASSOCIAÇÃO NACIONAL DOS AUDITORES FISCAIS DA RECEITA FEDERAL DO BRASIL (UNAFISCO). Tributação da distribuição de lucros e dividendos: a dupla não tributação de parte do lucro distribuído, estimativa arrecadatória da tributação de dividendos e propostas para equilíbrio da carga tributária, fev. 2020. p. 13.

40 Ibidem, p. 13-15.

${ }^{41}$ INTROÍNI, Paulo Gil Hölck et al.Tributação sobre a renda da pessoa física: isonomia como princípio fundamental de justiça fiscal, p. 276. In: ASSOCIAÇÃO NACIONAL DOS AUDITORES DA RECEITA FEDERAL DO BRASIL (ANFIP) e FEDERAÇÃO NACIONAL DO FISCO ESTADUAL E DISTRITAL (FENAFISCO). Eduardo Fagnani (organizador). A reforma tributária necessária: diagnósticos e premissas. Brasília: ANFIP, FENAFISCO. São Paulo: Plataforma Política Social, 2018. p. 245-280. 


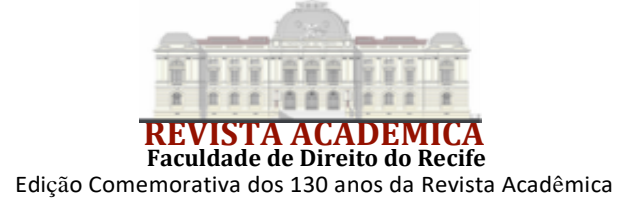

estudo, interessa que, em relação ao imposto de renda da pessoa física, há retenção definitiva na fonte à alíquota de $15 \%$, percentual este bastante inferior à alíquota máxima da tabela progressiva aplicável aos rendimentos do trabalho.

Quanto às aplicações financeiras, a sistemática de tributação difere sensivelmente a depender do tipo de investimento (renda fixa ou variável) e da modalidade em que são negociados os ativos (mercados à vista, de opções, futuro ou a termo), nos termos disciplinados pela Instrução Normativa RFB $\mathrm{n}^{\circ}$ 1.585/2015. Em todo caso, salvo no que diz respeito às operações títulos de capitalização, com pagamento de prêmios em dinheiro, mediante sorteio, sem amortização antecipada, a maior alíquota prevista para a tributação dos rendimentos provenientes de aplicações financeiras é de $25 \%$. Mais uma vez, portanto, menos gravosa que a alíquota a prevista para os rendimentos decorrentes do trabalho.

Por fim, o ganho de capital decorrente da transferência de bens e direitos é tributado no Brasil de forma definitiva, sujeitando-se a tabela progressiva com alíquota máxima de 22,5\%. Nesse ponto, além da tributação favorecida, é de se destacar ainda a postergação do fato gerador do imposto para o momento da realização do ativo. Ou seja, na hipótese em que um imóvel sofre reiterada valorização, ano após ano, o contribuinte somente precisará oferecer o ganho de capital à tributação em ocasião da venda do bem, inclusive se valendo dos fatores de redução previstos na legislação tributária.

Destaque-se, a propósito, que a tributação inequânime de rendimentos, coroada pela indevida concessão de isenções fiscais à elite brasileira, gera distorções por todo sistema tributário. Isso porque, como explica José Casalta Nabais, todos os direitos trazem consigo custos públicos, que, nos Estados físcais, são financiados primordialmente através da arrecadação de impostos ${ }^{42}$. Daí o alerta de Saldanha Sanches de que, embora os benefícios fiscais passem a falsa percepção de algo que sempre irá beneficiar os contribuintes, eles possuem um elevado custo para o sistema tributário, visto que a distribuição da carga fiscal é um jogo de soma zero ${ }^{43}$. A desoneração das elites, nesses termos, traz consigo a maior oneração das classes menos favorecidas, sobretudo por meio de impostos indiretos.

Por fim, se os rendimentos do capital e do trabalho são onerados de forma diferenciada, com a desoneração daqueles em detrimento destes, a situação fica ainda mais grave quando analisada sob o prisma da equidade vertical. Isso porque, no Brasil, a renda do capital cresce à medida em que se avança das faixas mais pobres para as mais abastadas da população ${ }^{44}$. Em outras palavras, quanto mais rica for uma pessoa, maior é a probabilidade de os seus rendimentos serem provenientes majoritariamente do capital e, portanto, de serem desonerados total ou parcialmente, em uma flagrante violação à progressividade e à justiça fiscal.

\section{CONSIDERAÇÕES FINAIS}

Como visto acima, sempre que a taxa de retorno do capital excede a taxa de crescimento da produção e dos salários, o sistema capitalista tende a gerar concentração de riqueza. Níveis persistentes de concentração de renda, por sua vez, são um incentivo à especulação e ao rentismo. Com efeito, desigualdade social e ineficiência econômica podem ser vistas como duas faces da mesma moeda.

Nesse contexto, a situação do Brasil é desoladora. O país figura entre os mais desiguais do

42 NABAIS, José Casalta. A face oculta dos direitos fundamentais: os deveres e os custos dos direitos, p. 22. Revista Direito Mackenzie, $\quad$ v. $3, \quad$ n. $2, \quad$ p. $\quad 9-30, \quad 2002 . \quad$ Disponível em: http://editorarevistas.mackenzie.br/index.php/rmd/issue/view/436. Acesso em: 12 abr. 2021.

43 SANCHES, J. L. Saldanha. Justiça Fiscal. Lisboa: Fundação Francisco Manuel dos Santos, 2016.

44 MORGAN, Marc. Income inequality, growth and elite taxation in Brazil: new evidence combining survey and fiscal data, 2001-2015. Working Papers n ${ }^{\circ}$ 165, International Policy Centre for Inclusive Growth, fev. 2018, p. 1923. Disponível em: https://ideas.repec.org/p/ipc/wpaper/165.html. Acesso em: 12 abr. 2021. 


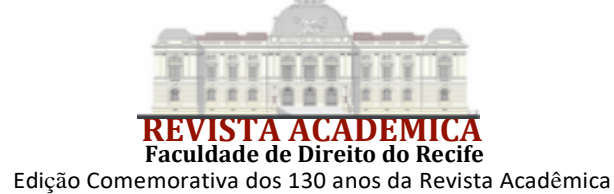

mundo. Apesar disso, ou por isso, temos um sistema tributário marcado por uma elevada regressividade. Em contrariedade às boas práticas internacionais, tributamos proporcionalmente mais o consumo e a produção, ao mesmo tempo em que desoneramos o patrimônio e a renda. Ao invés de funcionar como uma ferramenta de combate à concentração de renda, o ordenamento jurídico brasileiro acaba por trabalhar em prol dela, agravando uma realidade em si mesma periclitante.

Essa regressividade do sistema tributário nacional salta aos olhos quando paramos para analisar as normas que disciplinam o imposto de renda da pessoa física. A forma como os rendimentos são tributados no Brasil desafia os ditames da equidade horizontal e vertical. De um lado, não há igualdade no tratamento dos rendimentos do trabalho e do capital, sendo aqueles tributados de maneira mais gravosa que estes. De outro, a proporção dos rendimentos do capital cresce à medida em que se avança para as camadas mais abastadas da população, o que implica uma alíquota efetiva mais baixa para a elite econômica.

Diante de tais circunstâncias, conclui-se que as regras de tributação no Brasil são não apenas injustas e perversas, pois atuam para manter o abismo que separa uma minúscula elite econômica do restante dos brasileiros; representam, também, um verdadeiro empecilho ao desenvolvimento econômico do país. A solução não é nada simples, mas é possível apontar algumas sugestões, sendo a mais premente delas a revogação da isenção do imposto de renda da pessoa física sobre o recebimento de lucros e dividendos. Feito isso, já teremos percorrido algum caminho.

\section{REFERÊNCIAS}

\section{ASSOCIAÇÃO NACIONAL DOS AUDITORES FISCAIS DA RECEITA FEDERAL DO}

BRASIL (UNAFISCO). Tributação da distribuição de lucros e dividendos: a dupla não tributação de parte do lucro distribuído, estimativa arrecadatória da tributação de dividendos e propostas para equilíbrio da carga tributária, fev. 2020

\section{ASSOCIAÇÃO NACIONAL DOS AUDITORES DA RECEITA FEDERAL DO BRASIL (ANFIP) e FEDERAÇÃO NACIONAL DO FISCO ESTADUAL E DISTRITAL}

(FENAFISCO). Eduardo Fagnani (organizador). A reforma tributária necessária: diagnósticos e premissas. Brasília: ANFIP, FENAFISCO. São Paulo: Plataforma Política Social, 2018.

BERG, Andrew G.; OSTRY, Jonathan D. Inequality and unsustainable growth: two sides of the same coin? Fundo Monetário Internacional, abr. 2011, p. 13. Disponível em: https://www.imf.org/external/pubs/ft/sdn/2011/sdn1108.pdf. Acesso em: 12 abr. 2021.

CARVALHO, Aurora Tomazini de. Curso de teoria geral do direito: o constructivismo lógicosemântico. 4. Ed. São Paulo: Noeses, 2014.

DABLA-NORRIS, Era et al. Causes and consequences of income inequality: a global perspective. Fundo Monetário Internacional, jun. 2014. Disponível em: https://www.imf.org/en/Publications/Staff-Discussion-Notes/Issues/2016/12/31/Causes-andConsequences-of-Income-Inequality-A-Global-Perspective-42986. Acesso em: 12 abr. 2021.

HIRSCHMAN,Albert O. The rhetoric of reaction: perversity, futility, jeopardy. Cambridge, Londres: The Belknap Press of Harvard University Press, 1991.

JHERING, Rudolf von. Bromas y veras en la jurisprudencia: un regalo de Navidad para los lectores de obras jurídicas. Trad. Tomás A. Banzhaf. Buenos Aires: Ediciones Juridicas Europa- 
America, 1974.

KUZNETS, Simon. Economic growth and income inequality. American Economic Review, v. 45, n. 1, p. 1-28, mar. 1995.

MORGAN, Marc. Income inequality, growth and elite taxation in Brazil: new evidence combining survey and fiscal data, 2001-2015. Working Papers $n^{\circ} 165$, International Policy Centre for Inclusive Growth, fev. 2018. Disponível em:

https://ideas.repec.org/p/ipc/wpaper/165.html. Acesso em: 12 abr. 2021.

PIKETTY, Thomas. Capital in the twenty-first century. Trad. Arthur Goldhammer.

Cambridge, London: The Belknap Press of Harvard University Press, 2014

POCHMANN, Márcio. Desigualdade econômica no Brasil. São Paulo: Ideias \& Letras, 2015.

MELO, Luciana Grassano de Gouvêa. Desigualdade, Covid-19 e tributação dos super ricos. In: MACHADO SEGUNDO, Hugo de Brito et al. A pandemia da Covid-19 no Brasil em sua dimensão financeira e tributária. Belo Horizonte, São Paulo, 2020, p. 151-164.

MELO, Luciana Grassano de Gouvêa. Para entender o papel da tributação na desigualdade. In: MELO, Luciana Grassano de Gouvêa (org.). Justiça Fiscal. Estudos Críticos de problemas atuais. Belo Horizonte: Ed. Letramento, 2020. p. 21-36.

NABAIS, José Casalta. A face oculta dos direitos fundamentais: os deveres e os custos dos direitos. Revista Direito Mackenzie, v. 3, n. 2, p. 9-30, 2002. Disponível em:

http://editorarevistas.mackenzie.br/index.php/rmd/issue/view/436. Acesso em: 12 abr. 2021

SALDANHA, Nelson. Da teologia à metodologia: secularização e crise do pensamento jurídico. Belo Horizonte: Del Rey, 1993.

SANCHES, J. L. Saldanha. Justiça Fiscal. Lisboa: Fundação Francisco Manuel dos Santos, 2016.

VIEHWEG, Theodor. Tópica e jurisprudência. Brasília: UnB; Brasília: Ministério da Justiça, 1979.

WARAT, Luiz Alberto. Introdução geral ao direito II: a epistemologia jurídica da modernidade. Porto Alegre: Sergio Antonio Fabris Editor, 1995. 